\title{
Children's Acceptability of Mid Day Meal (MDM) Food Supplied from Centralized Kitchen-“Akshaya Patra” of Medak District
}

\author{
Nagaraj Swathi*, K. Uma Devi and S. Suchiritha Devi
}

Department of Foods and Nutrition, Hyderabad, Professor Jayashankar Telangana State Agricultural University, Andhra Pradesh, India

*Corresponding author

\section{A B S T R A C T}

\begin{tabular}{|l|}
\hline Keywords \\
Children, \\
Acceptability, Mid \\
Day Meal (MDM)
\end{tabular}

Keywords

Children,

Acceptability, Mid

Meal (MDM)

\begin{abstract}
A present study was conducted on children's acceptability of mid-day meal (MDM) food supplied from centralized kitchen-"akshayapatra" of medak district in Telangana state. A multistage stratified random sampling was used for selection of schools in the selected districts. Altogether, 150 children (with an equal representation of boys and girls) studying from Class I to Class VIII, belonging to 3 schools were selected with reasonable distribution of MDM that enabled evaluating food in terms of its acceptability, quantity, quality, taste, texture and flavor. From the study it was observed that all the children from the schools of Medak had MDM served only during lunch break and consumed food in the school premises itself. It was encouraging to know that all the dishes served in mid-day meal were mostly preferred by children. The children were given varied dishes like kichidi, rice and dal, rice and sambar, vegetable pulav, tamarind rice, fried rice, jeera rice, fruits and other snacks like groundnut chikki, biscuits, pickles, etc.
\end{abstract}

\section{Introduction}

Malnutrition adversely affects Universalization of Elementary Education (UEE). Even if a malnourished child does attend school, he/she finds it difficult to concentrate on and participate in the learning activities in school. Children's acceptance of MDM was elicited through a simple opinion questionnaire, executed by the researcher, compiled and drawn the inferences. The acceptability of food items served was computed from the individual responses on six aspects of food namely, quantity; quality; taste, texture, flavour and appearance, and overall acceptability. Unable to cope, the child would very often drop out of school. To combat classroom hunger and promoting better learning, school meals has been realized as an important means of protecting children's right to food.

In November 2001, an interim order of the Supreme Court of India directed that cooked meals must be provided in all government and government-aided primary schools. By converting the provision of a midday meal into a legal entitlement for all school-going children. Following pressure from the Supreme Court as well as from popular mobilization, the government of India introduced a revised midday meal scheme 
(MDMS) in 2004 which is future revised in 2006, increasing the calorie content of the meal to 450 calories (from 300 calories) and protein to 12 grams (from 8-12 grams).

Currently, the government of India contributes grain for the midday meal (100gms per child per day) free of cost through the Food Corporation of India and a sum of Rs 1.50 per child per day towards cooking costs, on the condition that state governments contribute at least $50 \mathrm{p}$ per child per day. Additionally, the government of India contributes some amount towards transportation charges and monitoring and evaluation (GoI, 2006).

Many independent studies have been done on the MDMS by researchers and civil society organizations. These studies suggest that this scheme has many benefits such as increasing enrolment and attendance in schools, especially of girl children, and addressing the issue of classroom hunger, thereby also increasing learning ability (Drèze and Goyal, 2003). The MDMS also has large socialization and educational benefits. However, these studies have also found that there is still a lot to be achieved as far as the quality of the midday meal is concerned. For instance, in many places the same menu is given every day (usually roti or rice and a watery dal or sambar) with no vegetables, eggs, fruits and so on (Khera, 2006).

Sen (2005) reported that MDM has made positive intervention in universalisation of Primary Education by increasing enrolment, attendance of the children. Mathur (2005) revealed that Cooked Mid Day meal has reduced classroom hunger especially those belonging to underprivileged sections. Cooked mid day meal has also contributed to the cause of social equity as children, cutting across caste and class lines sit together to share a common meal.
Cooking and Serving of MDM is done by Self Help Groups (SHG's) from organizations like Development of Women and Children in Rural Areas DWCRA or presently from Society for Elimination of Rural Poverty (SERP) in the state of Telangana. As part of public private partnership, Akshaya Patra Foundation has been engaged to serve MDM to cover more than 2 lakh children. The Akshaya Patra Foundation is a not-for-profit organisation headquartered in Bengaluru, India. The organisation strives to fight issues like hunger and malnutrition in India, by implementing the Mid-Day Meal Scheme in the Government schools and Governmentaided schools. Akshaya Patra aims not only to fight hunger but also to bring children to school.

There is a lot of difference in the acceptability of MDM in schools, more so in places where the food supplies are from a centralized kitchen. In view of the above, the study was planned with an objective to assess the children's acceptability of MDM from Akshaya Patra model. Hence the study entitled "Children's Acceptability of Mid Day Meal (MDM) Food Supplied from Centralized Kitchen-'Akshaya Patra' of Medak district."

The Akshaya Patra Foundation (TAPF) food was fresh, hygienic and nutritious. It was reported that they faced problems and suggested that for monitoring and evaluation of the programme, registers and monitoring forms should be made simpler. As teachers play an important role, they can encourage children to consume the meals and sensitize them for good hygiene and sanitation practices (Shruti et al., 2013).

Mohanty (2014) revealed that the problems associated with MDM were, insufficient food which lead to dissatisfaction among the parents and students, no separate room for serving food and eating and poor quality of 
raw ingredients. Irregular releases of funds and salaries to the cooks were making cooks not satisfied.

Mallik (2008) conducted a study to find out the best practices in the implementation of MDM Scheme in Orissa and found that providing eggs twice in a week (Wednesday and Friday), serving rice and dal along with the mixed vegetables twice or thrice a week and serving homemade pickle to the children during lunch hour were some good and acceptable practices in MDM.

Sahoo (2014) in a study reported that taste and smell of the food need to be improved but the appearance and texture were quite appropriate. All the students were satisfied with MDM program and there was no significant association between student's satisfaction level and the demographic variables.

\section{Materials and Methods}

A multistage stratified random sampling was used for selection of schools in the selected districts. Altogether, 150 children (with an equal representation of boys and girls) studying from Class I to Class VIII, belonging to 3 schools from 3 Mandals namely Pothireddypally, Sadashivpet and Hathnurof Medak district were selected for the study.

Akshaya Patra Foundation was implementing the MDM school through its Centralized Kitchen located at Patancheru mandal. The methods adopted for the study mainly included questionnaire for acceptability of MDM and perception of teachers and community.

Children's acceptance of MDM was elicited through a simple opinion questionnaire, executed by the researcher, compiled and drawn the inferences. The acceptability of food items served was computed from the individual responses on six aspects of food namely, quantity; quality; taste, texture, flavour and appearance, and overall acceptability.

\section{Results and Discussion}

The results of the present study was presented below

In Medak district, MDM was served by Akshaya Patra Foundation, through its Central Kitchen and preparations like kichidi, rice and dal, rice and sambar, vegetable pulao, tamarind rice, fried rice, jeera rice were the major alternative meals, while fruits were served twice in a week and other snacks like chikki, tilladoo, mixture, etc. were served in addition to meal. Unlike other MDM kitchens, serving of boiled egg once or twice a week was not a practice of Akshaya Patra, as only satwik food is preached by the Akshya Patra.Evaluation of acceptability of food served under MDM by Akshya Patra by the children revealed the following facts.

Kichidi served from Akshaya Patra was rated 'good' for quantity by $99 \%$, quality by $35 \%$, taste by $88 \%$, texture by $85 \%$, flavor by $89 \%$, appearance by $91 \%$ and overall acceptability by $91 \%$ by the children. Almost $30 \%$ of the children rated the quality of kichidi as 'average' or 'poor' due to its less spicyness.

Rice and dal was rated good for quantity by $100 \%$, quality by $89 \%$, taste by $87 \%$, texture by $86 \%$, flavor by $99 \%$, appearance by $99 \%$ and overall acceptability by $99 \%$. Almost all the children rated 'good' for rice and dal. Only $12 \%$ rated 'average' for texture due to liquidity of the dal. Rice and sambar was rated good for quantity by $93 \%$, quality by $91 \%$, taste by $82 \%$, texture by $85 \%$, flavor by $98 \%$, appearance by $97 \%$ and overall acceptability by $100 \%$. The overall acceptability of rice and sambar was $100 \%$. Only $10 \%$ rated rice and 
sambar as 'poor' for taste. Due to plastic cans used by Akshaya Patra, the taste and flavor of the food has been changing.

Vegetable pulao was rated 'good' for quantity of $37 \%$, quality by $87 \%$, taste by $85 \%$, texture by $85 \%$, flavor by $44 \%$, appearance by $45 \%$ and overall acceptability by $45 \%$. It was rated 'poor' for quantity by $29 \%$ due to insufficiency serving and flavor as 'poor' by $33 \%$ due to packing of hot pulav in plastic cans, poor rating for appearance by $33 \%$ was due to lack of color and less amount of vegetables used to prepare vegetable pulao and overall acceptability by $33 \%$.

Tamarind rice was rated 'good' for quantity by $93 \%$, quality by $90 \%$, taste by $81 \%$, texture by $79 \%$, flavor by $89 \%$, appearance by $89 \%$ and overall acceptability by $86 \%$. Almost $18 \%$ rated tamarind rice as 'average' in texture due to softness of the rice and over use of tamarind pulp.

Fried rice was rated 'good' for quantity by $95 \%$, quality by $73 \%$, taste by $83 \%$, texture by $87 \%$, flavor by $89 \%$, appearance by $82 \%$ and overall acceptability by $88 \%$. Almost $10 \%$ rated fried rice as 'average'. Jeera rice was rated 'good' for quantity by $99 \%$, quality by $91 \%$, taste by $84 \%$, texture by $85 \%$, flavor by $77 \%$, appearance by $77 \%$ and overall acceptability by $73 \%$. Taste was rated poor by $9 \%$ for jeera rice due to the lack of seasoning.

Fruits served twice a week were rated good for quantity by $91 \%$, quality by $84 \%$, taste by $86 \%$, texture by $87 \%$, flavor by $100 \%$, appearance by $91 \%$ and overall acceptability by $89 \%$. Fruits was rated poor for quality by $14 \%$ due to the spots on banana and witherness of oranges, etc. other snacks like chikki, mixture, thilladoo etc., were rated good for quantity by $89 \%$, quality by $95 \%$, taste by $73 \%$, texture by $91 \%$, flavor by $44 \%$, appearance by $87 \%$ and overall acceptability by $80 \%$. Almost $23 \%$ rated poor for taste and $26 \%$ rated 'poor' for flavor of snacks due to old stock. One major observation from Akshya Patra was that boiled egg was not provided which was an important nutritive food for the children (Fig. 1).

Figure.1 Overall acceptability of the children on MDM

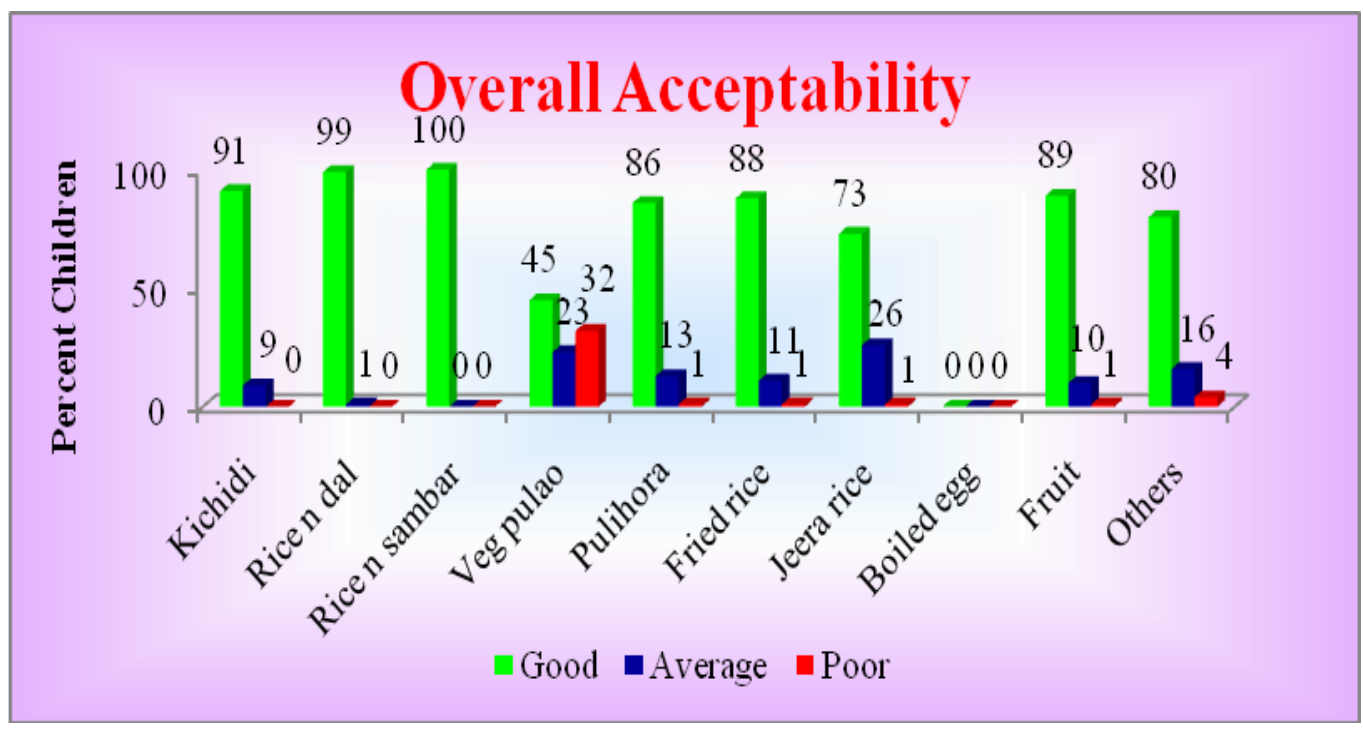


From the study it was observed that all the children had MDM served only during lunch break and consumed food in the school premises itself. It was encouraging to know that all the dishes served in mid-day meal were mostly preferred $(100 \%)$ by children. The acceptability of food items served were computed from the individual responses on six aspects of food (Quantity; Quality; Taste; Texture, Flavour and Appearance), and the overall acceptability of the children for all the items ranked between; 45 and 100\% in Medak, indicating Good acceptability.

Parents of school children and the teachers were also satisfied with the MDM obtained through Akshya Patra, but absence of egg in MDM was a concern for them. As per Govt. norms and as a food being liked and well accepted for its taste and nutrition it was felt and expressed by the community that inclusion of egg will be beneficial.

Because the delivery of the food was too early, the food was getting cold by the time it was served to children. Buttermilkwas getting heated up due to use of plastic cans and leaving the cans outside in the hot sun for a long time in school grounds. Dhal preparations especially sambar was dilute up to $3 / 4^{\text {th }}$ of the cans due to the improper dispersion of dhal mash and due to high depth of the cans mixing could not be done effectively while serving.

\section{References}

Commissioners of the Supreme Court (2007): 'Seventh Report of the Commissioners', New Delhi, available at www.sccommissioners.org

GoI(2006): 'National Programme of Nutritional Support to Primary Education, 2006:
Guidelines', Ministry of Human Resources Development, Government of India, New Delhi.

GoAP (2007): 'Mid-Day Meal Scheme: Annual Work Plan for 2007-08', Government of Andhra Pradesh.

Drèze, J and Goyal (2003): The Future of MidDay Meals, Economic \& Political Weekly, November 1, pp 4673-82.

Khera, R (2006): 'Mid-Day Meals in Primary Schools: Achievements and Challenges', Economic \& Political Weekly, November 18, pp 4742-50.

Sen,A. (2005). Cooked mid day meal programme in West Bengal-A study in Birbhum district, Pratichi Trust.

Mathur,B.(2005). Situation Analysis of MDM Programme in Rajasthan,University of Rajasthan and UNICEF.

Shruti, K., Uma, I., Swati, D and Hemangini, G. 2013. Perceptions of municipal school teachers of urban vadodara on strengths and weaknesses of mid-day meal programme: voices from the ground. Journal of Community Nutrition and Health. 2(2): 26-31.

Mohanty, S.P. 2014. Practice of mid-day meal scheme at elementary education level: a case study of a rural elementary school. Scholars Journal of Arts, Humanities and Social Sciences. 2(3):402-407.

Mallik, A. 2008. A study of best practices in the implementation of mid-day meal programme in Orissa. National University of Educational Planning and Administration.1-42.

Sahoo, P. 2014. A descriptive study on effectiveness of mid-day meal programme in selected government primary school of Bhubaneshwar, Odisha. International Journal of Extensive Research. 9: 26-31.

\section{How to cite this article:}

Nagaraj Swathi, K. Uma Devi and Suchiritha Devi, S. 2018. Children's Acceptability of Mid Day Meal (MDM) Food Supplied from Centralized Kitchen-"Akshaya Patra" of Medak District. Int.J.Curr.Microbiol.App.Sci. 7(07): 107-111. doi: https://doi.org/10.20546/ijcmas.2018.707.013 